\title{
Documentos relacionados con el Visir Amen-Hotep, Huy, dueño de la tumba no -28- en Asasif. (Luxor Occidental)
}

\author{
Documents related to the Vizier Amen-Hotep, Huy, \\ owner of the tomb no. -28- at Asasif. (Luxor- West Bank)
}

\author{
Francisco J. Martín Valentín \\ TERESA BEDMAN*
}

\begin{abstract}
RESUMEN
ABSTRACT

Los documentos y monumentos relacionados con el Visir Amen-Hotep, Huy, que desempeñó su función como

Visir del Sur en los años finales del reinado de Amen-Hotep III (dinastía XVIII, hacia 1358-1353 a. C.) son muy escasos, en comparación con los referidos a otros personajes del mismo periodo. El motivo principal de esta oscuridad es, sin duda, el hecho de haber sido perseguida su memoria, y destruidos sus monumentos.

Este artículo tiene por objeto publicar la compilación de los documentos arqueológicos y textuales conocidos, relacionados con el Visir Amen-Hotep, Huy, hasta el momento en que, en el año 2009, se inició por el Instituto de Estudios del Antiguo Egipto de Madrid la exploración y excavación sistemática de la tumba no-28-, construida por orden del Visir Amen-Hotep, Huy, en la necrópolis de Asasif (Luxor Occidental).

\section{PALABRAS CLAVE:}

Amenhotep III, Visir del Sur, Asasif, Tumba, Amen-Hotep Huy, Tumba no-28- , Instituto de Estudios del Antiguo Egipto.

The documents and monuments connected with the vizier Amen-Hotep, Huy, who was Vizier of the South, at the end of the reign of Amen-Hotep III (XVIIIth. dynasty c.1358 - 1353 BC), are very scarce, compared with referrals to other courtiers in the same period. The main reason for this darkness is, without doubt, the fact of having been persecuted his memory, and his monuments, destroyed.

This article aims to publish the compilation of known archaeolgical and textual documents, in relation with the Vizier Amen-Hotep, Huy, before 2009, when the Instituto de Estudios del Antiguo Egipto of Madrid started the systematic exploration and excavation in the tomb No. 28-, built by order of this high royal functionary, in the necropolis of Asasif (Luxor West Bank).

\section{KEYWORDS:}

Keywords: Amenhotep III, Southern Vizier, Asasif, Tomb, Amen-Hotep Huy, Tomb no-28- , Instituto de Estudios del Antiguo Egipto.
\end{abstract}

* Instituto de Estudios del Antiguo Egipto (Madrid) email: martinvalentin@ telefonica.net. 
Nuestra amistad con el Profesor Lara Peinado se remonta al año 1987, cuando, con motivo de la celebración de un simposio entre alumnos de la Facultad de Geografía e Historia de la Universidad Complutense de Madrid, cuyo tema era la Historia antigua de Egipto, tuvimos el placer de conocerle personalmente.

Desde entonces, y hasta hace muy poco tiempo, nuestra relación fue profunda y muy fructífera. Con su inestimable colaboración, siempre entusiasta y desinteresada, el día 14 de octubre de 2005, fundamos la Cátedra de egiptología 'José Ramón Mélida', en el seno de la Fundación General de la Universidad Complutense de Madrid, que tan excelentes frutos dio durante su existencia.

Pero fueron muchas más las actividades que, durante cerca de veinte años, realizamos juntos en pro de la egiptología. Siempre fue un amigo fiel, dotado de una humanidad y una filantropía sin parangón. Gran ser humano, gran erudito, y gran profesor, tales son las esenciales virtudes que, a nuestro parecer, adornan la persona del Profesor Lara Peinado.

Hoy es para nosotros un honor, y constituye una enorme satisfacción, colaborar con nuestro testimonio de agradecimiento y amistad al merecido homenaje que se le rinde por sus colegas, alumnos y amigos, al término de su entregada y generosa carrera académica.

El Visir Amen-Hotep, Ilamado Huy, fue un personaje, hoy poco conocido, del periodo de Amen-Hotep III (1387 - 1348 a. C.).

Los documentos y monumentos relacionados con él son escasos en comparación con los referidos a otros personajes del mismo tiempo. El motivo principal de esta oscuridad es, sin duda, el hecho de haber sido perseguida su memoria, y destruidos sus monumentos.

La exploración de su tumba, la Tumba no -28- de Asasif, identificada por primera vez por Andrew Gordon como la del Visir Amen-Hotep, Huy, ${ }^{1}$ no se ha llevado a cabo hasta el presente de un modo exhaustivo. Esta tumba se encuentra en la zona de Asasif sur, prácticamente inédita, sin excavar, hasta que se puso en marcha el 'Proyecto Visir Amen-Hotep, Huy' del Instituto de Estudios del Antiguo Egipto, ahora hace cuatro años.

\section{LOS DOCUMENTOS}

Los documentos conocidos, relacionados con el Visir Amen-Hotep, de los que disponemos, son los siguientes:

\footnotetext{
1 Hasta el momento solo se han llevado a cabo exploraciones del monumento por Andrew Gordon de la Universidad de California, a instancias y en compañía de Dieter Eigner, en mayo de 1978, con motivo de la elaboración de la planimetría de las tumbas existentes en Asasif sur.

Cfr. GORDON, A.: "The Tomb of the Vizier Amenhotep at Thebes". MDAIK 39 (1983), pág. 72 y, "Who Was the Southern Vizier during the Last Part of the Reign of Amenhotep III?". JNES 48 (1989), pp. 15-23.
} 
A) Dos improntas de sello de jarra encontradas en Malkata referidas al primer Heb-Sed de Amen-Hotep III (Año 30 del reinado) 2:

A') «Perfecta medida de ofrendas de comida y bebida hecha por el Visir Huy para este Heb-Sed». (Hayes, JNES 10, 1951, ํo 103)

B') «Aceite de moringa del Visir Huy para este Heb-Sed». (Hayes, JNES 10, 1951, ํㅡㄴ 185)

En estas inscripciones queda patente que Amen-Hotep era ya, durante la celebración de este primer Jubileo ${ }^{3}$ de Amen-Hotep III, Visir, si bien, no podemos determinar con precisión a la vista de las mismas, si del Sur (Tebas), o del Norte (Menfis).

B) Una estela (BM 138) conteniendo una copia del Decreto de fundación del Templo funerario de Amen-Hotep, Hijo de Hapu (Año 31 del reinado).

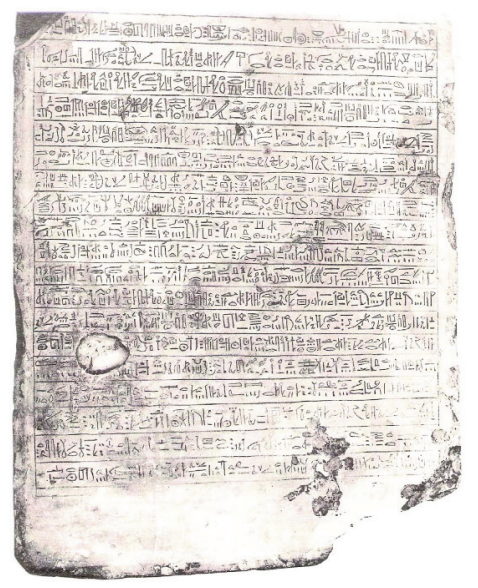

Fig. 1. Decreto de la Fundación del Templo funerario de Amen-Hotep, Hijo de Hapu Estela BM 138 De VARILLE, A. y ROBICHON, C. Op. cit. 1936, Pl. 1

El texto del Decreto de la fundación dice:

"Año 31, cuarto mes de la inundación, día 6, bajo la Majestad del Rey del Alto y del Bajo Egipto, Señor de las Dos Tierras, Neb-Maat-Ra (vida, salud y fuerza), el

${ }^{2}$ La identificación del Visir Huy con Amen-Hotep viene dada por no tener evidencias de la existencia de ningún otro Visir de Amen-Hotep III durante su jubileo del año 30, aparte de Ra-Mose y de Amen-Hotep, constando que el término Huy era un apelativo familiar alternativo de Amen-Hotep, usado frecuentemente durante el Imperio Nuevo y, especialmente durante la dinastía XVIII. Cfr. GORDON, A. Op. cit. 1983, pág. 77

3 La sola mención del término $p A H b$-sd, sin citar alguna de las fechas de los años 30, 34 o 37, induce a pensar en el primero celebrado por el Rey en el año 30 de su reinado, como aquel al que se deben vincular estas inscripciones. 
hijo de Ra de su propia carne, el Señor de las Coronas, Amen-Hotep (III), vida, salud y fuerza.

En este día (el Rey) estaba en la fundación funeraria del noble escriba real Amen-Hotep. Fueron introducidos: el Visir Amen-Hotep, el gobernador del Tesoro Mery-Ptah y los escribas reales del ejército.

Les fue dicho en presencia de Su Majestad, vida, salud y fuerza: « iEscuchad el decreto para regular la fundación funeraria del noble escriba real Amen-Hotep, Ilamado Huy, hijo de Hapu, hecho a causa de sus perfecciones, a fin de perpetuar por siempre su fundación funeraria en lo concerniente a sus esclavos de los dos sexos, de hijo en hijo y de heredero en heredero, y de prohibir que se les aparte nunca jamás!.

Está colocada bajo la protección de Amón-Ra, Rey de los Dioses, por tanto tiempo como dure sobre la tierra, pues Él es el Rey de la eternidad y el protector de lo que a los difuntos conviene.

En cuanto al Jefe de las Tropas, Escriba de las Tropas, que vendrá después de mí y que encontrará la fundación funeraria caída en la decadencia con los esclavos de ambos sexos que cultivan las tierras para mis ingresos, (en cuanto a ese hombre), si tomare personal entre mis gentes para colocarlo en cualquier servicio del Faraón, vida, salud y fuerza, o para encargarle de trabajos que le interesen personalmente, en cuanto a cualquier otro que les apartase (de la fundación), sin asumir su responsabilidad por este asunto, que sea expuesto a la maldición de Amón, Señor del Trono de las Dos Tierras, que reside en su Harén.

Él no les permitirá disfrutar del cargo de escriba real de las tropas que recibieron gracias a mí. Él les entregará al fuego del Rey en su día de cólera. El Ureus de su frente vomitará la llama sobre lo alto de sus cabezas, destruirá sus carnes y devorará sus cuerpos. Serán igual que Apofis en «la Mañana del Día del Año». Naufragarán en el mar que tragará sus cadáveres. No recibirán los honores debidos a las gentes virtuosas. No podrán recibir las ofrendas de los muertos. No se les verterá en libación el agua del cauce del río. Sus hijos no ocuparán sus lugares. Sus mujeres serán violadas ante sus ojos. Los Grandes no se desviarán hasta sus casas, mientras estén sobre la tierra. Los ujieres de Palacio no los introducirán. No escucharán las palabras del Rey cuando él esté alegre. Serán entregados al cuchillo en el día de la masacre. Se les tratará como a la serpiente Apofis. Sus cuerpos perecerán pues tendrán hambre y no tendrán alimentos y sus cuerpos morirán.

En lo que concierne al Visir, al Gobernador del Tesoro, al Gran Intendente del Dominio Real, al Ministro de los Graneros, los Primeros Profetas, los Padres Divinos y los sacerdotes de Amón, a los cuales se habrá leído mi acta hecha para la fundación funeraria del noble escriba real Amen-Hotep, hijo de Hapu, que no vigilasen sobre su fundación funeraria, que les alcancen las maldiciones de más arriba.

Pero si al contrario ellos velan sobre la fundación funeraria en lo que concierne a los siervos de los dos sexos que cultivan las tierras para mis ingresos, que les 
sea hecho todo el bien posible. Amón, Rey de los dioses, os gratificará con una sólida duración de vida. El Rey que reine en vuestra época os recompensará como él sabe recompensar. Para vosotros, los cargos se acumularán sobre los cargos que recibiréis de hijo en hijo y de heredero en heredero. Serán enviados en misiones (reales) y el Rey de su tiempo les proveerá de todas las cosas. Serán enterrados en la necrópolis después de haber alcanzado la edad de ciento diez años, y para ellos se multiplicarán las ofrendas.

De igual modo, en lo que concierne a los Jefes de Policía, al Gobernador del Distrito, al Gobernador del oeste de Tebas que no controlen con el sello los productos de mis rentas cada día y en todas mis fiestas del primer día del mes que les alcancen las maldiciones de más arriba y que sus cuerpos sean aplastados.

Pero si, al contrario, ellos obedecen todas las prescripciones anotadas en el decreto, si ellos se muestran devotos y no olvidan nada, les alcanzará el bien como a los Justos y reposarán en la necrópolis después de la vejez.

Excepción hecha en favor del Gobernador del Oeste: Él utilizará mis servidores por un sólo día». ${ }^{4}$

Este documento, cuyo texto está datado el día 6 del cuarto mes de la estación de la inundación (Ajet) del año 31 de Amen-Hotep III, recoge el acto de la fundación del Templo funerario de Amen-Hotep, Hijo de Hapu, un relevante personaje del reinado de Amen-Hotep III que llegaría a ser divinizado durante la baja Época. En el mismo se recoge la presencia del Visir Amen-Hotep en presencia del Rey para escuchar y refrendar la orden real en relación con dicho asunto. El texto ha sido objeto de múltiples comentarios para tratar de encontrar un motivo por el que, siendo Ra-Mose Visir del Sur en aquellos momentos, según todas las evidencias, tales como su tumba en Tebas (TT 55), no comparece en dicho acto y, en cambio sí lo hace Amen-Hotep Huy.

Una de las tesis propuestas es que Ra-Mose habría desaparecido a finales del año 30 y le habría sucedido en el cargo Amen-Hotep, quien era ya en aquel momento Visir del Norte. ${ }^{5}$ Otra propone reconocer en Amen-Hotep al auténtico Visir

${ }^{4}$ De ROBICHON, C. et VARILLE, A. Op. cit. 1936, pp. 5-7.

5 'Ramose, fue Visir del Sur durante un plazo muy breve que debió transcurrir entre los años 28 al 30 de Amen-Hotep III. Sabemos que en el año 31, ya no era Visir ocupando su lugar otro personaje Ilamado Amen-Hotep.

El templo funerario de Amen-Hotep hijo de Hapu sería concluido alrededor de su fecha de fallecimiento, a principios del año 31 de Amen-Hotep III, o algo después. Se conoce una estela (B. M. 138) que recoge el decreto de la fundación del templo. Está fechada en el año 31 de Amen-Hotep III, pero sin duda se trata de una copia reproducida durante la dinastía XXI, en el Tercer Periodo Intermedio (hacia el año 1050 a. de C.) durante la reconstrucción del templo funerario ya en ruinas para esa época. Se trató de un acto piadoso realizado por los sumos sacerdotes de Amón que protegieron también las momias reales de los faraones del Imperio Nuevo enterrándolas en otras tumbas colectivas.... Así pues, Amen-Hotep, Huy, fue el siguiente Visir del Sur, después de Ramose.

Es probable que también ejerciera, al mismo tiempo, el cargo de Visir del Norte. Lo que es seguro, es que, cuando se dictó el decreto protector de la fundación funeraria de Amen-Hotep hijo de Hapu, fechado en el año 31 del Rey, quien compareció como Visir en tal acto fue este Amen-Hotep. 
del Sur, mientras que Ra-Mose lo era del Norte, siendo su tumba (TT 55) un cenotafio construido en la necrópolis de Tebas, capital religiosa de Egipto en aquel momento. ${ }^{6}$

C) Diversos restos de monumentos con inscripciones procedentes de las canteras del Guebel El Silsila.7

\section{C.1. La Capilla 'A'}

Se trata de una capilla excavada en la pared rocosa de la zona norte del Guebel El Silsila, situada algo al este de una estela de Amen-Hotep IV. En su interior tiene una estela esculpida.

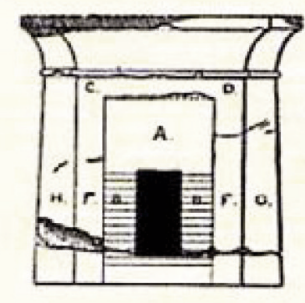

Fig. 1.

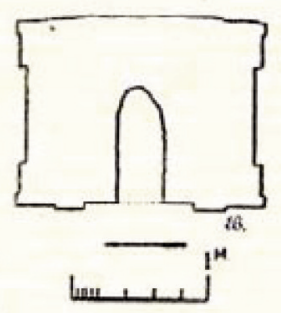

Fig. 2.

Fig. 2. Capilla A. LEGRAIN, G. Op. cit. 1904, fig. 1 y 2

Se construyó para él una tumba en Asasif, la más grande conocida de la necrópolis de Tebas, aunque está muy deteriorada. Es curioso el hecho de que, además, está inacabada. ...'.

MARTÍN VALENTÍN, F. J. Amen-Hotep III, el esplendor de Egipto. Madrid, 1998, 125-126. LEGRAIN, G. ASAE, 4 (1904), 197 y ss.

6 GORDON, A. Op. cit. 1989, 20-23

7 LEGRAIN, G. ASAE 4 (1904), Notes d'Inspection, IV. 197-212 
El texto de las doce líneas que sobreviven dice:

«Año 35, día primero de Shemu, bajo [la Majestad del de Nebty:] el que establece las leyes, el que pacifica las Dos Tierras, el del Horus de Oro: El que es grande de fuerza (cuando) golpea a los asiáticos, el Rey del Alto y del Bajo Egipto, el Señor de las Dos Tierras 'Neb-Maat-Ra, la imagen de Ra' [el hijo de Ra Amen-Hotep Heka Uaset]...su júbilo. El soberano que no tiene igual. (Él) somete a los principales de todas las tierras extranjeras, su poder golpea a todos los Jefes de....su frontera del Sur (llega) hasta el inicio de la tierra de Jent-hen-Nefer (y) está bajo su terror, (su frontera) del norte (llega) hasta los pilares del cielo de Jemu-Kemet. (Ellos) vienen humildemente a causa de su grito guerrero. No tiene oponente en todas las tierras (ni entre) los principales de los países extranjeros. Los que pertenecen a Su Majestad vienen trayendo sus corazones a su Señor, junto con sus espaldas...Adorar a su diosa Uadyit (Úreus). ¡Sus capillas Shetyt están en sus corazones. Los Bau de Su Majestad (están) en cada estación. Ellos rinden homenaje a su Úreus.... Ios monumentos para su padre [Amón] en Ipet Sut... La llegada oculta de Su Majestad. Hacer las ofrendas alimentarias en su tiempo...»

Amen-Hotep, cuya efigie está martilleada y borrada, está representado en los espacios existentes junto a los montantes derecho e izquierdo.

Inscripciones en el cuadro de la derecha:

Traducción:

«Dando adoración a Sobek-Ra, oliendo el suelo en Jeni (Silsila). Yo doy adoro su presencia, yo exalto su belleza diariamente. Apaciguarle con las ofrendas diarias. Hacer alabanzas de su bello rostro, ¡Que él conceda diariamente entrar y salir del Palacio Real y la regeneración junto con los favores del Rey para el Ka de Aquel que está sobre los secretos en el Palacio Real de ...la tierra hasta su confín!. Invocación (hecha) como (expresión de) gran poder del que es llamado [Huy]. Adoración sincera del [Inspector de... Amen-Hotep]».

Inscripciones en el cuadro de la izquierda:

Traducción:

«Adoración de Amón, oliendo el suelo para el Señor de los dioses, el único augusto, sin igual, el que preside Ipet-Sut, el buen dios amado, Superior de todos los dioses. ;Darle la adoración y las ofrendas diarias, hacer grande su belleza, más que a los otros dioses!. ¡Que él conceda la duración del tiempo de vida conforme a su decreto, una bella tumba conforme a los favores del Rey para el Ka del noble príncipe, el depositario del sello del Rey del Norte, el amigo único, los dos ojos del Rey en la tierra entera, el favorito en su palacio, el Inspector de todas las obras....[el Visir Amen-Hotep...]!».

Inscripciones en el montante derecho:

Traducción: 
"Adorar al buen dios, oliendo el suelo para el Señor de las Dos Tierras, el poderoso rey...el hijo protector, el Toro-de-su-Madre, poderoso de fuerza como el hijo de Isis, el grande de poder como el Señor de Tebas, el que es poderoso de corazón como el hijo de Nut........ El elegido como su hijo. ¡Hacer que tú seas el Señor único sobre la tierra!.

(Hecho) por el [noble príncipe], el Depositario del Sello del Rey del Norte, Grande en el Palacio Real, La Boca Única (el portavoz del rey), el que está satisfecho....llamado [Huy]».

Inscripciones en el montante izquierdo:

Traducción:

«Adorar al buen dios, oliendo el suelo para el Señor de las Dos Tierras, el Rey poderoso amado de Jenum, el que construye los cuerpos con la crecida de un Hapy grande, el que recuenta los días del año, el que hace vivir el corazón de los dioses. ¡Nosotros te vemos, nosotros te contemplamos como a Ra en el cielo!. ¡Nosotros no te diferenciamos de Hor-Ajty...! El noble eficiente para Su Señor, el que está a los pies del Señor de las Dos Tierras [Amen-Hotep]”.

\section{C.2.- Dos estelas (B y $C$ de $G$. Legrain)}

\section{C.2.1.- Estela B:}

Inscripciones a la derecha de la efigie del oferente cuya efigie ha sido borrada:

Traducción:

«Adorar al buen dios, oliendo el suelo para el Señor de las Dos Tierras por el noble príncipe, el Depositario del Sello del rey del Norte, el amigo único, la Boca única que habla cuando las otras bocas están en silencio... Amen-Hotep...»

Inscripciones a la izquierda de la efigie del oferente cuya efigie ha sido borrada:

Traducción:

«Adorar al Toro poderoso, oliendo el suelo para el que aparece radiante en la Maat por el noble...el conocido del Rey, el Consejero de Confianza llamado [Huy]. Adoración sincera del aquel cuya utilidad es grande, ... Amen-Hotep...»

\section{C.2.2.- Estela C:}

Debajo de la representación del Rey Amen-Hotep III junto a dos dioses cuyas imágenes han sido borradas, subsiste el siguiente texto:

«Año [35]...el que aparece radiante sobre la Maat, el de Nebty: el que establece las leyes [para pacificar las Dos Tierras]... Su Majestad...su augusto templo...Atum-Ra en este, su lugar de residencia eterna, el Mesjenet ('el lugar de nacimiento') que perdura para él eternamente en armonía en su interior. 
Documentos relacionados con el Visir Amen-Hotep, Huy...

Su hijo, el protector con sus seguidores, consigue para Él (Amón) infinita cantidad de cientos de miles de lo más selecto de todas las tierras extranjeras.

Restaura Tu Ureus. Promueve Tu aparición radiante con poder.

(Él) ha invocado para Ti la aparición radiante sobre tu trono, Neb-Maat-Ra (Amen-Hotep III), el que es amado por Ti.

Verdaderamente este Gran Rey ha concebido el plan para buscar la imagen sagrada del halcón, buscando después lo que es provechoso, haciendo lo que es útil delante de su excelso padre, la forma de su belleza; haciendo hábilmente su extracción (de la piedra) para Él (Amón). Las aguas vienen de él, a causa de su permanente prestigio como el poder mágico de aquel que está al frente de Rehesut (Osiris). Él posee el conocimiento (que sale de) su corazón para (ejecutar) los trabajos que (hacen) bella la apariencia del dios. Él le conoce (a Amón) como su hijo, haciendo lo que es provechoso; él hace aumentar las ofrendas divinas, haciendo la ofrenda divina de alimentos para esta tu Eneáda.

Haciendo para Él los monumentos, restaurándolos por tres veces. No se había visto nada parecido a estas provisiones en toda la tierra. No se había hecho (nada parecido) por los reyes antepasados de Su Majestad, dando las instrucciones para todas las obras.»

\section{C.3.- El naos 'E'}

Muy degradado. A ambos lados del mismo existen dos estelas. La del lado sur está completamente destruida.

La del lado norte conserva esta inscripción:

Traducción:

«[El Horus Toro Poderoso que aparece radiante en Maat, el de Nebty, El que establece las leyes], el que pacifica las Dos Tierras, el del Horus de Oro...... el Rey del Alto y del Bajo Egipto [Neb-Maat-]Ra, dotado de vida, el Hijo de Ra [Amen-Hotep, Heka Uaset]....... de numerosas provisiones...las maravillas de [Amón]... satisfecho con...todos los frutos excelentes...como Rey de las Dos Tierras. Él hace reverdecer para él las Dos Orillas, ofreciéndole la Corona Blanca, así como la Corona Roja.

La Doble Corona (Sejemty) es estable como su cabeza. Todas las Tierras de los pueblos Feneju (los Sirios) y todas las tierras extrajeras están doblegadas bajo las sandalias de este buen dios.» 


\section{C.4.- El naos 'F'}

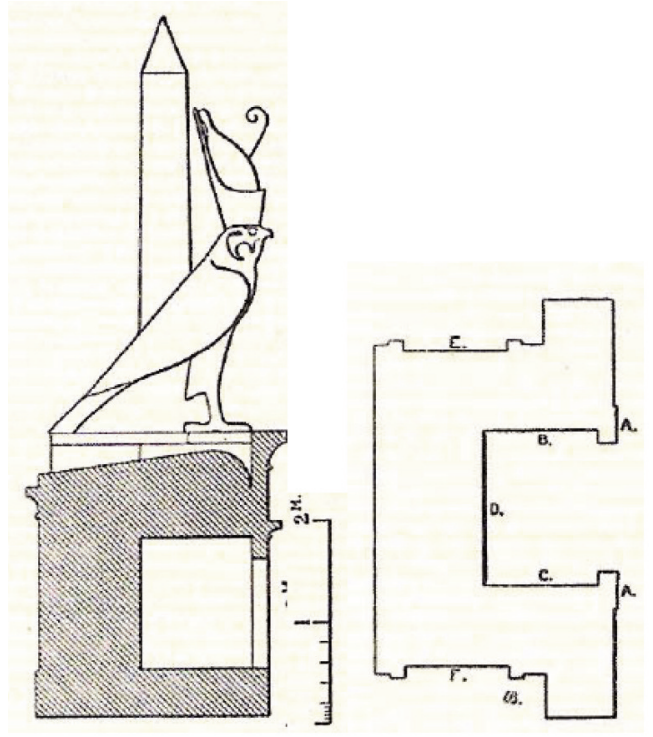

Fig. 3. El naos F reconstruido. Sección y planta. Legrain, G. Op. cit. 1904, fig. 3

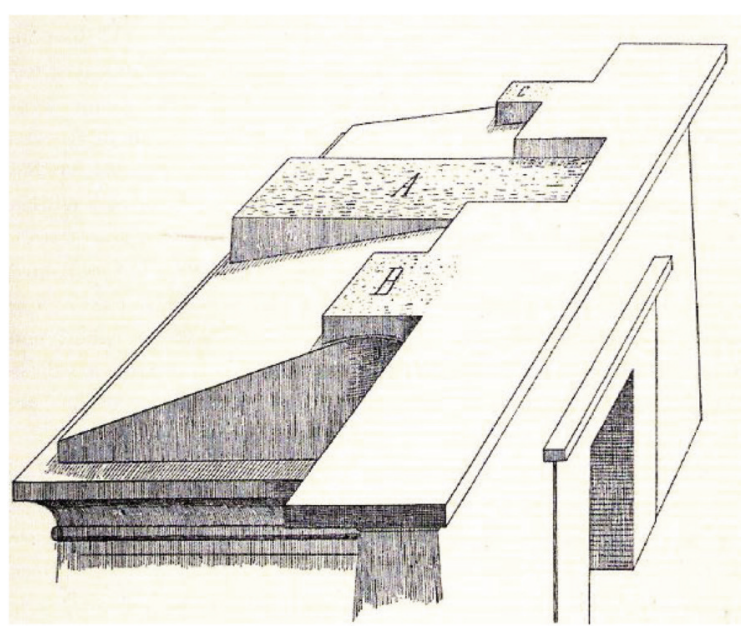

Fig. 4. El naos F reconstruido. Perspectiva caballera. Legrain, G. Op. cit. 1904, fig. 4 
Legrain encontró esta capilla partida en dos grandes trozos y arrancada de su base. En la parte superior estaban dispuestos un halcón tocado con la doble corona y un obelisco. La cámara interior estaba decorada en sus tres paredes.

En la pared B (interior) se ve la figura borrada de un personaje.

Subsiste el siguiente texto:

«Adorar a Ra en lo alto del cielo, divino de sus transformaciones, único...con todos los que viven en la Verdad, diariamente... El buen dios, el Amado, el Superior de la Gran Eneáda, el Buen Gobernante que aparece radiante con la Corona Blanca.»

En la pared C (interior) se ve la figura borrada de un personaje.

Subsiste el siguiente texto:

Traducción:

«Adorar al Rey del Alto Egipto Neb-Maat-Ra, dotado de vida....el noble príncipe...él dice:

'Homenaje a ti, Rey poderoso, Amado [de Amón], hijo de un Hapy grande, el que hace vivir a Kemet. ¡Que el deseado viento del Norte (esté ) en su boca!. ¡El de rostro satisfecho, el poderoso, el Toro poderoso de Ra, de agudos cuernos...! .«

Los textos consisten en oraciones laudatorias a Sobek, a Amón-Ra y a la condición divina del Rey Amen-Hotep III como soberano poderoso que favorece y trae la crecida del Nilo, asociando al propio Amen-Hotep a la figura del Rey, como era tradicional, como fiel servidor que esperaba gozar del favor real a cambio de la lealtad y los servicios prestados al monarca.

La presencia de Amen-Hotep en el Guebel El Silsila en el año treinta y cinco del reinado tenía por fundamento la extracción de bloques de piedra de las canteras de arenisca para las construcciones que, al parecer, aún continuaban en los templo de Amón en el Ipet Sut y en el Ipet Reshut en Tebas ${ }^{8}$, puesto que Georges Legrain descubrió muy cerca de las capillas los restos de esfinges criocéfalas del dios Amón, como las empleadas en las avenidas de esfinges de ambas construcciones. ${ }^{9}$ Además es segura que en ese tiempo también se estaba construyendo el magnífico templo funerario del Rey en la orilla occidental de Tebas en Kom el Heittan.

Los textos fueron severamente perseguidos, probablemente por los seguidores de Aj-en-Aton y, por lo que atañe al Visir Amen-Hotep, todo parece indicar que cayó en desgracia y su memoria fue severamente perseguida, siendo borradas su nombre, su Ka y sus imágenes, llegando a cubrirse en alguna parte su efigie, ya martilleada con una capa de color anaranjado que hacía más completa la destrucción de la personalidad del Visir. ${ }^{10}$

\footnotetext{
8 Templos de Karnak y Luxor

9 LEGRAIN, G. Op. cit. 1904, 209

10 Ibidem, 212
} 
Títulos de Amen-Hotep que figuran en los monumentos del Guebel El Silsila referidos a Amen-Hotep Huy, cuya efigie ha sido destruida:

«1ํ El que está sobre los secretos del Palacio real...en la tierra entera hasta su confín

$2^{\circ}$ El Inspector de...

$3^{\circ}$ El noble príncipe depositario del sello del Rey del Norte, el amigo único, los ojos del Rey en la tierra entera hasta su confín, el favorito en la casa del Rey, el Inspector de...

$4^{\circ}$ El cortesano eficiente, el asistente del Señor de las Dos Tierras...

$5^{\circ}$ El noble príncipe, el igual del Rey del Norte, el que es grande en la Casa real, el heraldo único a la izquierda de él (el Rey)

$6^{\circ}$ El noble príncipe, el noble príncipe, el igual del Rey del Norte, el amigo único, la boca que habla cuando las (otras) bocas están en silencio.....Amen-Hotep

$7^{\circ}$ El conocido del Rey, el Consejero de Confianza llamado [Huy]. Adoración sincera del aquel cuya utilidad es grande, ... Amen-Hotep...

$8^{\circ}$ El noble príncipe

9 El noble príncipe, el amigo único, el Inspector.....Amen-Hotep»

\section{D) La carta EA71 del archivo de El Amarna}

«A Haya (Huy), el Visir: Mensaje de Rib-Hadda.

Yo caigo a tus pies. Que Aman (Amón), el dios del Rey, tu señor, establezca tu honor delante del Rey, tu señor. Tú eres un hombre sensato; el Rey lo sabe, y a causa de tu buen sentido él te ha enviado como Comisario. ¿Por qué has sido negligente no hablando al Rey para que envie arqueros para tomar Sumur?. Entonces ¿quién es Abdi-Ashirta, servidor y perro, para tomar el país de mi Rey para él mismo?. ¿De qué clase es su tropa auxiliar para que sea tan poderosa?. ¡Su tropa auxiliar es poderosa a causa de los Apiru!. ¡Envíame también cincuenta troncos de caballos y doscientos infantes de modo que yo pueda resistirle hasta la llegada de los arqueros!. ¡Que él no reúna a todos los Apiru, de modo que podría capturar Shigata y Ampi, y apoderarse de...!. (En tal caso) ¿Qué podría hacer yo?: ino habría lugar donde se podría penetrar contra él!».

(Traducción a partir de MORAN, L. W. Op. cit., 1987, pp. 246-247)

La identificación del personaje a quien se dirige la misiva del príncipe RibHadda con el Visir (Amen-Hotep) Huy ha sido aceptada por todos los especialistas.

En tal caso, parece que Amen-Hotep habría sido comisionado por el propio Rey Amen-Hotep III para hacer una gira de inspección en los lugares de in- 
fluencia egipcia en Siria, concretamente a la zona de lo que más adelante sería Biblos.

E) Las estatuas CG 590 y BM 1068, procedentes de Bubastis11

\section{E.1 Estatua CG 590}

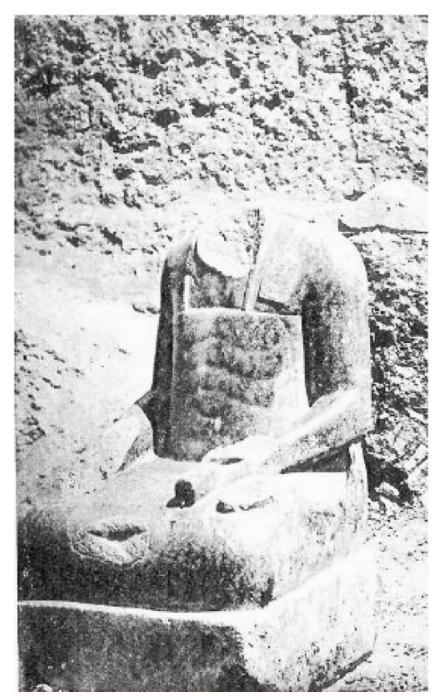

Fig. 5. Estatua CG590 del Visir Amen-Hotep, Huy.

NAVILLE, E. Bubastis (1887-1889). EEFM VIII, Londres 1891, pág. 31, PI. XIII

En el rollo de papiro que tiene entre las manos está inscrito el siguiente texto:

«Haciendo las leyes, estableciendo la Maat, dictando las instrucciones por el noble príncipe, el gran amigo de su señor, el Director de todas las obras de su Rey en los nomos de Shobak del Bajo Egipto ${ }^{12}$, el depositario del sello del Rey del Norte, el Alcalde, el Visir Amen-Hotep, Señor de la veneración».

\section{E.2 Estatua BM 1068}

En una columna vertical en el centro de su vestido está inscrito el siguiente texto:

11 NAVILLE, E. Bubastis (1887-1889). EEFM VIII, Londres 1891, pp. 31-33 y PI. XIII y XXXV

12 HABACHI, L. Tell Basta. El Cairo, 1957, 106, pág. 112. 


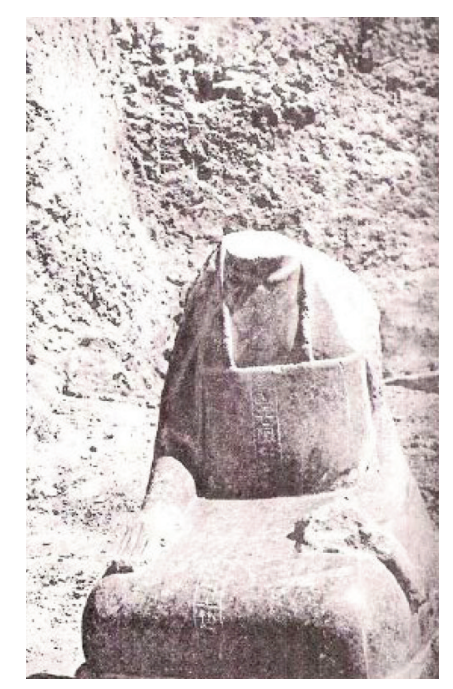

Fig. 6. Estatua BM 1068 del Visir Amen-Hotep, Huy.

NAVILLE, E. Bubastis (1887-1889). EEFM VIII, Londres 1891, pág. 33, PI. XXXV

\section{Traducción del texto:}

«El noble que cuida los dominios de los templos, el principal de Nejen que hace alto en su marcha en la tierra sagrada, el Alcalde, el Visir Amen-Hotep, que vuelve a vivir».

El hallazgo de estas dos estatuas en Tell El Basta, en el templo, sugiere a los especialistas que Amen-Hotep fue enviado allí, bien para supervisar las obras que habrían de hacerse en los recintos religiosos del lugar con motivo de la celebración del Heb-Sed del año 30 de Amen-Hotep III, o en su camino hacia Biblos, para inspeccionar la situación en aquel punto de Siria. ${ }^{13}$ Sin embargo, en atención a la traducción de la estatua de El Cairo (CG 390), parece que su responsabilidad se atendría en ese momento solo a las obras del Bajo Egipto. ${ }^{14} \mathrm{Si}$ se admite la interpretación de Gordon ${ }^{15}$ que traduce el título citado en esta estatua como Director de todas las obras de su Rey en el Alto y el Bajo Egipto, estaríamos en presencia de la posibilidad de admitir que Amen-Hotep no estaba vinculado solo al Norte del país en el ejercicio de sus funciones administrativas.

\footnotetext{
13 GORDON, A. Op. cit. 1989, pp. 18-20

${ }_{14}$ LABACHI, L. Op. cit. 1957, pp. 121-122

15 GORDON, A. Op. cit. 1989, pp. 18-20
} 


\section{F. Un relieve en el Templo de Soleb}

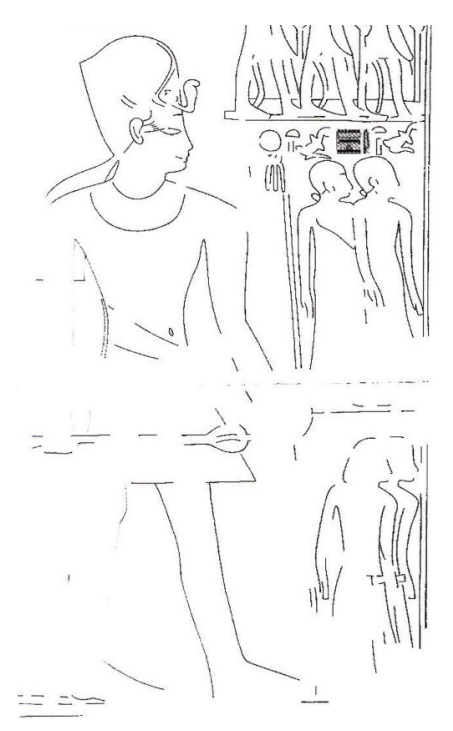

Fig. 7. Los Visires Amen-Hotep y Ra-Mose en el Templo de Soleb A partir de SCHIFF GIORGINI, M. Soleb V. Le Temple. Bas-reliefs et inscriptions.

El Cairo, 1998. PI. 42

En el ala Norte del pórtico Este del primer patio del Templo de Soleb figura una escena representativa de la ceremonia de la inauguración del Templo donde se divinizó Amen-Hotep III con motivo de su primera fiesta jubilar. ${ }^{16}$

Allí se ven dos personajes delante del Rey cuyas inscripciones adjudican los títulos de Visir para ambos. El nombre del primero ha sido destruido, mientras que el del segundo se lee claramente: Ra-Mose. En base a ello se ha propuesto reconocer en el otro personaje a Amen-Hotep Huy, cuya memoria fue perseguida y su nombre destruido en los monumentos. Gordon ha propuesto a la vista de este documento, aplicando la comprensión de la escena como la figuración por orden protocolario (Alto y Bajo Egipto) de los dos Visires en funciones en ese momento, el reconocimiento de Amen-Hotep como Visir del Alto Egipto, mientras que Ra-Mose lo habría sido del Norte. ${ }^{17}$

16 LEPSIUS, K. R.- Denkmäler aus Aegypten und Aethiopien. Berlín, 1849-1859. Abt. III, PI. 83, b) SCHIFF GIORGINI, M. Soleb V. Le Temple. Bas-reliefs et inscriptions. El Cairo, 1998. PI. 42

17 GORDON, A. Op. cit. 1989, pp. 20-22 


\section{CONCLUSIONES:}

A la vista de todos los documentos que anteceden podemos concluir que Amen-Hotep, Ilamado Huy, fue cortesano del rey Amen-Hotep III y ejerció el cargo de Visir, primero solo del Bajo Egipto, y en un momento determinado, asumió también el visirato del Sur, en Tebas.

Los documentos que conocemos le referencian con los años treinta, treinta y uno y treinta y cinco de Amen-Hotep III. Ello quiere decir que, al menos, tenemos constancia de que Amen-Hotep Huy ejerció el visirato entre los años treinta al treinta y cinco del reinado.

La cuestión a debatir y aclarar es cual fue la secuencia de los acontecimientos en el 'cursus honorum' de Amen-Hotep. ¿Fue desde el principio de su nombramiento el Visir del Sur con residencia en Tebas?, o, alternativamente, ¿fue originariamente Visir del Norte y asumió, después de la desaparición de Ra-Mose, el visirato del Sur?.

En nuestra opinión, por el momento, esta segunda alternativa es la más plausible, a la espera de conocer nuevos datos sobre el personaje que pudieran sernos revelados, a partir de nuestras excavaciones en la Tumba no -28- de Asasif.

Las inscripciones de jarra descubiertas en Malkata solo evidencian la presencia de Amen-Hotep, como Visir (no precisan si del Sur o del Norte) en las primeras ceremonias jubilares (en el año treinta) del Rey Amen-Hotep III. Por otra parte, es perfectamente lógico y coherente que el Visir del Norte estuviera presente en tan trascendentes ceremonias. Ra-Mose también estuvo presente en dicho jubileo como consta por sus propias etiquetas de jarra con su nombre halladas en Malkata $^{18}$. Esta evidencia se confirma con la presencia conjunta de ambos Visires en la inauguración del Templo de Amen-Hotep III en Soleb. La representación en primer lugar de Amen-Hotep delante de Ra-Mose quizás tenga que ver más con una cuestión de antigüedad en el ejercicio del cargo de Visir que con una cuestión de protocolo en virtud de la cual la mención en las inscripciones y relieves del Alto Egipto debía anteceder siempre a la del Bajo Egipto.

Por otra parte, sabemos que con el antecesor de Ra-Mose y de Amen-Hotep en el ejercicio del visirato, en este caso de los del Alto y del Bajo Egipto conjuntamente, había sido el Sumo Sacerdote de Amón, Ptah-Mose.

Por ello es plausible pensar que al cese de Ptah-Hotep se nombraran dos Visires: uno para el Alto Egipto, Ra-Mose, y otro para el Bajo Egipto, Amen-Hotep.

La existencia de las dos estatuas de Bubastis, halladas junto a restos de otra del Mayordomo de la Reina Tiy, Jeruef, en el mismo lugar solo evidencia que ambos personajes dejaron sus testimonios en el templo de Bastet con motivo, probablemente, de los preparativos del primer jubileo del Rey. Aquí, Amen-Hotep se

18 HAYES, W. Op. cit. 1951, no 96 
nos muestra como Visir ejerciendo sus funciones en el Norte, por tanto, como Visir del Norte. Sus títulos son típicos del funcionariado del Norte y muy parecidos a los de otros personajes del Norte.

Sin embargo, sí poseemos la evidencia de que en el año treinta y uno, AmenHotep comparece en Tebas en su calidad de Visir, en el acto de la fundación del Templo funerario de Amen-Hotep, Hijo de Hapu. En dicho momento no está presente Ra-Mose, luego hay que suponer que éste había cesado en su cargo como Visir del Sur, lo que debió suceder entre el año treinta y el año treinta y uno del reinado y, consecuentemente, que Amen-Hotep había asumido la función de Visir del Sur a partir del cese de aquél.

Sabemos que, en el año treinta y cinco del reinado, Amen-Hotep continuaba ejerciendo el cargo de Visir del Sur (quizás al mismo tiempo que del Norte tal como ya había sucedido en tiempos de Ptah-Mose) por sus textos inscritos en las canteras del Guebel el Silsila, luego, se nos abre un periodo desde el año treinta y uno al treinta y cinco, en el que Amen-Hotep habría sido indiscutiblemente el Visir del Sur y, probablemente y al mismo tiempo Visir del Norte, puesto que no conocemos a nadie que lleve este título durante dicho periodo del reinado.

Con toda verosimilitud fue durante este periodo de cuatro a cinco años cuando se realizaron las obras de excavación de su tumba en Tebas, en la zona del Asasif. Ordena que se excave en la misma zona de la necrópolis donde el Mayordomo de la Reina Tiy, otro prestigioso funcionario real, se había hecho construir la suya (TT192).

Parece claro que Amen-Hotep se inspiró en la tumba de Jeruef para construir la suya y que, en razón del estado de ejecución de ambas, la excavación de la de Jeruef se habría iniciado cierto tiempo antes de que lo fuera la de la tumba de Amen-Hotep.

Esto confirma que hubo un momento de coincidencia entre Jeruef y Amen-Hotep (los trabajos en Bubastis para el Jubileo real), en el que Amen-Hotep solo tenía el título de Visir del Norte.

Después del año treinta y cinco del reinado no volvemos a saber nada de Amen-Hotep. Consecuentemente, su cese como Visir del Norte y del Sur, debió producirse después de tal momento.

Sabemos que, como Visir del Sur, el siguiente llamado Najt ${ }^{19}$, residió en 'AjetAton' (Amarna), mientras que en Menfis fue nombrado Visir del Norte Aper-El ${ }^{20}$, quien ejerció tal función durante los dos o tres últimos años del reinado de AmenHotep III.

Dado el destruido estado de los monumentos y documentos que han llegado hasta nosotros hay que presuponer una persecución de la memoria de Amen-Ho-

19 VANDERSLEYEN, C. L'Égypte et la Vallée du Nil. (Tome 2). De la fin de l'Ancien Empire à la fin du Nouvel Empire. Nouvelle Clio, PUF, París, 1995, pág. 446

20 ZIVIE, A. Découverte à Saqqara. Le vizir oublié. Paris, 1990, pp. 115-123. 
tep Huy por parte de los funcionarios de Aj-en-Aton. También parece probable que la persecución de su memoria y la destrucción de su nombre, títulos e imágenes, se llevarían a cabo con motivo de su destitución y muerte, dado que se detecta una especial labor de destrucción de su personalidad y de su Ka. Ello implica que Amen-Hotep Huy fuera quizás uno de los más encarnecidos adversarios de las nuevas corrientes religiosas y, desde luego, un hombre muy vinculado con los cultos tradicionales de los dioses egipcios cuyos cleros sufrirían duramente la implantación del dios único Atón. 